\title{
Editorial: Screening for and Treatment of Moral Injury in Veterans/Active Duty Military With PTSD
}

\author{
Harold G. Koenig ${ }^{1,2,3 *}$, Donna Ames ${ }^{4,5}$ and Arndt Büssing ${ }^{6,7}$ \\ ${ }^{1}$ Department of Psychiatry and Behavioral Sciences and Department of Medicine, Duke University Medical Center, Durham, \\ NC, United States, ${ }^{2}$ Department of Medicine, King Abdulaziz University, Jeddah, Saudi Arabia, ${ }^{3}$ School of Public Health, \\ Ningxia Medical University, Yinchuan, China, ${ }^{4}$ Department of Psychiatry, VA Greater Los Angeles Healthcare System, Los \\ Angeles, CA, United States, ${ }^{5}$ Department of Psychiatry, David Geffen School of Medicine at UCLA, Los Angeles, CA, United \\ States, ${ }^{6}$ Quality of Life, Spirituality and Coping, Faculty of Health, Witten/Herdecke University, Witten, Germany, \\ ${ }^{7}$ IUNCTUS-Competence Center for Christian Spirituality, Philosophical-Theological Academy, Münster, Germany
}

Keywords: moral injury, PTSD, definition, screening, veterans

\section{Editorial on the Research Topic}

\section{Screening for and Treatment of Moral Injury in Veterans/Active Duty Military with PTSD}

\section{OPEN ACCESS}

\section{Edited and reviewed by:} Paul Stokes,

King's College London, United Kingdom

*Correspondence: Harold G. Koenig Harold.Koenig@duke.edu

Specialty section:

This article was submitted to Mood and Anxiety Disorders,

a section of the journal

Frontiers in Psychiatry

Received: 05 July 2019

Accepted: 29 July 2019

Published: 21 August 2019

Citation:

Koenig HG, Ames D and Büssing A

(2019) Editorial: Screening for and

Treatment of Moral Injury in Veterans/

Active Duty Military With PTSD.

Front. Psychiatry 10:596.

doi: 10.3389/fpsyt.2019.00596
Moral injury (MI) is a relatively new syndrome, yet one that has been around for a long time. MI often accompanies posttraumatic stress disorder (PTSD) and is especially common in active duty military $(\mathrm{ADM})$ and veterans as a result of combat experiences and other military-related traumas. MI may also be common in noncombat veterans, health professionals, and even civilian populations. The purpose of this Research Topic is to define and describe MI in veterans and ADM, examine how it is assessed and differentiated from PTSD, and begin to explore ways that psychiatrists and other health professionals can identify and address it. In this issue, we present perspectives and new research on MI from around the world, including the USA and Canada, Australia, France, and Germany.

When it occurs in the military, MI has been defined as the emotional, spiritual, and moral consequences of committing and/or observing others commit transgressions of deeply held moral values during combat or combat-related circumstances (1). Another common definition describes MI as "a betrayal of what's right, by someone who holds legitimate authority, in a high-stakes situation" (2), in other words, betrayal by commanders who may have placed service members in a position that forced them to transgress moral boundaries. Brief measures now exist that have been psychometrically validated to identify symptoms of MI among veterans and those currently in the military (3). Research has shown that $>50 \%$ of ADM with PTSD symptoms have four or more symptoms of MI in the severe range ( 9 or 10 on a 1-10 scale) (4), and nearly $60 \%$ of veterans with PTSD have five or more such symptoms (5).

In the past decade, we have learned that moral injuries of this type can have devastating consequences on mental health, causing severe anxiety, depression, hopelessness, and suicide among ADM and veterans (6). Given the many challenges involved in successfully treating military-related PTSD, clinicians are often so focused on PTSD symptoms and comorbid disorders (mood disorders, substance abuse, risk of suicide, etc.) that they fail to recognize underlying moral injuries that may be driving these disorders (1). Growing research suggests that PTSD and MI are distinct but overlapping conditions (7). Failure to recognize and address MI may impair successful treatment of PTSD, at least partly explaining why PTSD outcomes are so poor despite the best pharmacological and psychotherapeutic treatments now available (8).

While especially common in military settings, $\mathrm{MI}$ is also experienced by those outside the military. Much recent attention has been paid to rising suicide rates and burnout among physicians and nurses, which may be linked to moral injuries that occur in high stakes situations involving life and death decisions that these health professionals make (9). Likewise, victims of sexual and racial abuse may 
experience shame, guilt, anger, and undergo spiritual struggles. Although we focus here on MI acquired in military settings, future research should seek to identify and treat noncombat veterans, civilians in high-risk professions (physicians, nurses, police, firemen, other first responders), and those with a history of trauma (abuse, rape) who may experience similar symptoms.

New approaches to the treatment of MI in the setting of PTSD are now being developed and tested in randomized controlled trials $(10,11,12)$. These treatments provide hope and the promise of relief to millions of ADM and veterans who currently suffer from PTSD and related disorders. Before psychiatrists and mental health professionals can take advantage of these new treatments, however, they need to know how to identify MI, who to refer to, and what kinds of treatments are available to help those with a condition that may afflict more than half of current military personnel and veterans with PTSD symptoms. This Research Topic is designed to assist and inform in this regard.

In the first article, Koenig et al. review and discuss the definition of MI and the way that it has been conceptualized and measured among veterans and ADM, making recommendations for both investigators who conduct research in this area and clinicians who must screen for this syndrome in clinical practice. In the second article, Brémault-Phillips et al. briefly review past research on MI and mental health outcomes in the setting of PTSD among current and former military personnel. Next, Kopacz et al. illustrate this by exploring the association between loss of trust (a key symptom of MI) and mental health among 427 veterans and ADM with combat-related PTSD symptoms. Frankfurt et al. then delve into the mechanisms (direct and indirect pathways) by which MI occurs as a result of two specific types of military-related trauma in US Veterans, sexual trauma and combat exposure.

The next five articles focus on treatment. Belrose et al. present a new approach to the challenge of reintegrating soldiers with chronic PTSD back into civilian life in France. Carey and Hodgson follow

\section{REFERENCES}

1. Litz BT, Stein N, Delaney E, Lebowitz L, Nash WP, Silva C, et al. Moral injury and moral repair in war veterans: a preliminary model and intervention strategy. Clin Psychol Rev (2009) 29:695-706. doi: 10.1016/j.cpr.2009.07.003

2. Shay J. Achilles in Vietnam: combat trauma and the undoing of character. New York, NY: Scribner (1994).

3. Koenig HG, Ames D, Youssef N, Oliver JP, Volk F, Teng EJ, et al. Screening for moral injury - the moral injury symptom scale-military version short form. Mil Med (2018) 183(11-12):e659-65. doi: 10.1093/milmed/usy017

4. Volk F, Koenig HG. Moral injury and religiosity in active duty US Military with PTSD symptoms. Mil Behav Health (2019) 7(1):64-72. doi: 10.1080/21635781.2018.1436102

5. Koenig HG, Youssef NA, Ames D, Oliver JP, Teng EJ, Haynes K, et al. Moral injury and religiosity in U.S Veterans with posttraumatic stress disorder symptoms. J Nerv Ment Dis (2018) 206(5):325-31. doi: 10.1097/NMD.0000000000000798

6. Ames D, Erickson Z, Youssef NA, Arnold I, Adamson CS, Sones AC, et al. Moral injury, religiosity, and suicide risk in U.S veterans and active duty military with PTSD symptoms. Mil Med (2018) 184(3-4):e271-8. doi: 10.1093/milmed/usy148

7. Koenig HG, Youssef NA, Ames D, Teng EJ, Hill TD. Examining the overlap between moral injury and PTSD in U.S. Veterans and active duty military. J Nerv Ment Dis (2019).

8. Koenig HG, Boucher NA, Oliver JP, Youssef N, Mooney SR, Currier JM, et al. Rationale for spiritually-oriented cognitive processing therapy for with an article on how clinicians can identify and treat MI, drawing on their experience from Australia and illustrating the important role that military chaplains play in addressing this syndrome. Next, Büssing et al. draw on data from a large study of German soldiers, emphasizing the need to talk about experiences during combat, the need to forgive others, and the need to be forgiven for transgressions, ultimately leading to healing of moral injuries experienced during war. Purcell and colleagues then discuss why forgiveness is so important to US Veterans who feel guilt and shame about their actions in war, what type of forgiveness is attainable and meaningful, and what role clinicians can play in facilitating forgiveness. Finally, Smith-MacDonald et al. examine the spiritual dimensions of MI in the Canadian armed forces, describing what chaplains in this setting have to offer military personnel and their families.

This Research Topic promises to update readers on the latest research and discussions on this common, consequential, and often neglected syndrome. These articles will provide researchers with the best available tools to further explore the relationship between MI and mental health outcomes and to develop effective interventions, as well as inform and equip clinicians to identify MI in high-risk $\mathrm{ADM}$ and veterans and monitor response to treatment.

\section{AUTHOR CONTRIBUTIONS}

Each of the authors (HK, DA, and $\mathrm{AB}$ ) have contributed intellectual content and have contributed to the actual writing of the editorial.

\section{FUNDING}

Funding support for this article was provided by the Center for Aging and Human Development, Duke University Health Systems, Durham, North Carolina.

moral injury in active duty military and veterans with post-traumatic stress disorder. J Nerv Ment Dis (2017) 205(2):147-53. doi: 10.1097/ NMD.0000000000000554

9. Ford EW. Stress, burnout, and moral injury: the state of the healthcare workforce. J Healthc Manag (2019) 64(3):125-7. doi: 10.1097/JHM-D-19-00058

10. Harris JI, Erbes CR, Engdahl BE, Thuras P, Murray-Swank N, Grace D, et al. The effectiveness of a trauma focused spiritually integrated intervention for veterans exposed to trauma. J Clin Psychol (2011) 67:425-38. doi: 10.1002/jclp.20777

11. Litz BT, Lebowitz L, Gray MJ, Nash WP. Adaptive disclosure: a new treatment for military trauma, loss, and moral injury. NY, NY: The Guilford Press (2017).

12. Pearce M, Haynes K, Rivera NR, Koenig HG. Spiritually-integrated cognitive processing therapy: a new treatment for moral injury in the setting of PTSD. Glob Adv Health Med (2018) 7:1-7. doi: 10.1177/2164956118759939

Conflict of Interest Statement: The authors declare that the research was conducted in the absence of any commercial or financial relationships that could be construed as a potential conflict of interest.

Copyright (C) 2019 Koenig, Ames and Büssing. This is an open-access article distributed under the terms of the Creative Commons Attribution License (CC BY). The use, distribution or reproduction in other forums is permitted, provided the original author(s) and the copyright owner(s) are credited and that the original publication in this journal is cited, in accordance with accepted academic practice. No use, distribution or reproduction is permitted which does not comply with these terms. 